archives

of thermodynamics

Vol. 37(2016), No. 3, 109-138

DOI: $10.1515 /$ aoter-2016-0023

\title{
Validation of the generalized model of two-phase thermosyphon loop based on experimental measurements of volumetric flow rate
}

\section{HENRYK BIELIŃSKI *}

Institute of Fluid Flow Machinery, Polish Academy of Sciences, Fiszera 14, 80-231 Gdańsk, Poland

\begin{abstract}
The current paper presents the experimental validation of the generalized model of the two-phase thermosyphon loop. The generalized model is based on mass, momentum, and energy balances in the evaporators, rising tube, condensers and the falling tube. The theoretical analysis and the experimental data have been obtained for a new designed variant. The variant refers to a thermosyphon loop with both minichannels and conventional tubes. The thermosyphon loop consists of an evaporator on the lower vertical section and a condenser on the upper vertical section. The one-dimensional homogeneous and separated two-phase flow models were used in calculations. The latest minichannel heat transfer correlations available in literature were applied. A numerical analysis of the volumetric flow rate in the steady-state has been done. The experiment was conducted on a specially designed test apparatus. Ultrapure water was used as a working fluid. The results show that the theoretical predictions are in good agreement with the measured volumetric flow rate at steady-state.
\end{abstract}

Keywords: Thermosyphon loop; Two-phase flow; Minichannels

\section{Nomenclature}

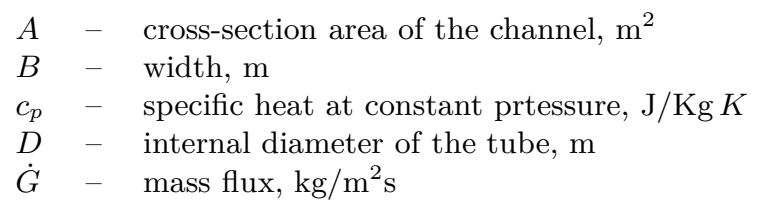

*E-mail: hbiel@imp.gda.pl 


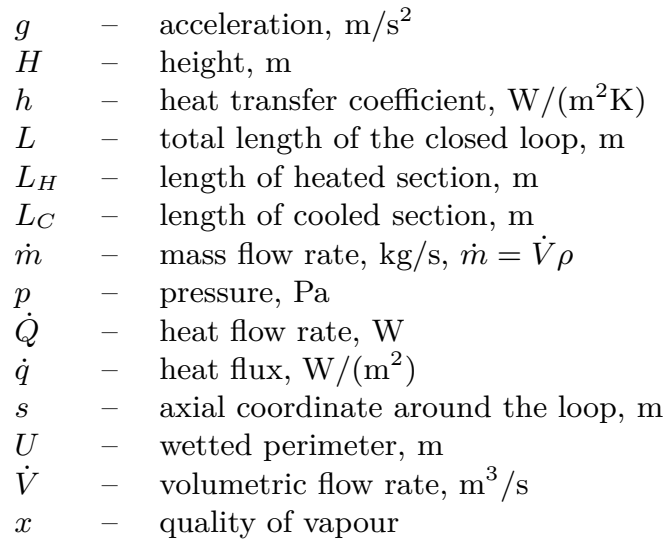

\section{Greek symbols}

$\alpha-$ void fraction, -

$\beta-$ volumetric coefficient of thermal expansions, $1 / \mathrm{K}$

$\varepsilon \quad-$ see Eq. (3)

$\rho \quad-\quad$ mass density, $\mathrm{kg} / \mathrm{m}^{3}$

$\tau_{w} \quad-\quad$ wall shear stress, $\mathrm{N} / \mathrm{m}^{2}$

$\lambda \quad-$ thermal conductivity, $\mathrm{W} / \mathrm{mK}$

\section{Subscripts and superscripts}

\begin{tabular}{|c|c|c|}
\hline$C$ & - & cooler \\
\hline$H$ & - & heater \\
\hline$i, j, k, n$ & - & indices \\
\hline$L$ & - & liquid \\
\hline$V$ & - & vapour \\
\hline $1 P, 2 P$ & - & single-, two-phase \\
\hline$L 0$ & - & liquid phase only \\
\hline$F r$ & - & friction \\
\hline$L O C$ & - & local \\
\hline$s s$ & - & steady-state \\
\hline TOT & - & total \\
\hline & - & reference of steady sta \\
\hline
\end{tabular}

\section{Other symbols}

$$
<\cdot>\quad-\text { per unit of time }
$$

\section{Introduction}

Trend towards the miniaturization of electronic devices creates specific heat dissipation problems. The two-phase thermosyphon loop has been extensively investigated for its possible applications in the cooling systems of electronic devices by many researchers [1-5]. In fact, there is still a need 
for further studies to understand the thermosyphon cooling process.

The main purpose of this study is to present the experimental validation of the generalized model of two-phase thermosyphon loop. The generalized model of the two-phase thermosyphon loop and its different variants were demonstrated in previous papers [2,6-12]. This paper presents the theoretical analysis and the experimental data obtained for a new designed variant particularly suited for computer cooling requirements. The variant refers to a thermosyphon loop with both minichannels and conventional tubes. The thermosyphon loop consists of an evaporator on the lower vertical section and a condenser on the upper vertical section. The presented variant configuration with the evaporator (single-conventional tube) and condenser (single-minichannel tube) has not previously been experimentally investigated by other researchers. A numerical prediction of the volumetric flow rates in the steady-state has been done by examining the presented variant. The experiment was conducted on a specially designed test apparatus. Ultrapure water was used as a working fluid.

The generalized model is based on conservation equations of mass, momentum, and energy balances in the evaporators, rising tube, condensers and the falling tube. The one-dimensional homogeneous and separated twophase flow models were used in calculations. The one-dimensional model was analyzed because the ratio of the channel loop diameter to the length of the channel was negligibly small. The results of these models were compared in terms of the volumetric flow rate. The generalized model can predict the thermosyphon loop system characteristics such as volumetric and mass flow rate, mass flux, heat transfer coefficient in flow boiling and condensation in minichannels and conventional tubes, local and friction resistance for a single- and two-phase flow in thermosyphon loop, geometrical parameters of the loop, thermal parameters of the heaters and coolers, stability of the onset of a global fluid motion in thermosyphon loop. One of the most important parameters used to describe the flow behavior and thermal performance of a natural circulation inside the thermosyphon loop is the volumetric and mass flow rate. The mass flow rate depends on properties of working fluid.

Many simulation studies have been undertaken to investigate the heat transfer behavior and two-phase fluid flow in the thermosyphon loop. Because of a lack of understanding about the dynamic nature of the flow and heat transfer in a thermosyphon, there is an increasing demand for validation experiments. Lamaison et al. [13] presented and validated a novel 
dynamic simulation tool for predicting the behavior of a two-phase minithermosyphon with microchannels. Both the mini-thermosyphon and simulation tool was successfully applied for the retrofitting of a commercial server by cooling its two CPU processors. The study shows that a $30 \%$ increase in the riser diameter led to $60 \%$ increase in the mass flow rate depending on the heat flux. The multi-microchannel evaporator model was presented. The predicted mass flow rates demonstrate the gravity dominant regime (GDR) at low heat flux and the friction dominant regime (FDR) at high heat flux. Comparisons with the experimental values of mass flow rate are planned. Archana et al. [14] investigated the flow initiation transient and steady-state flow in the natural circulation loop. Their results were also validated by experiments. Authors suggested that the oscillations in the mass flow rate are caused by the friction force and buoyancy force. A steady state is reached when the buoyancy force is balanced by the frictional force. The mass flow rate increases with the increase in the power. They reported a very high amplitude oscillation at low power start-up. This peak of amplitude confirmed the existence of type I instability in the first unstable zone in the two-phase region. Lemos et al. [15] studied the correlation between two-phase flow pattern and thermal behavior of a natural circulation loop. Authors reported the results of flow rate measurements. The flow rate oscillations were identified. The oscillations exceeded a certain value (plateau) by running the experiment. The visualization of two-phase natural circulation flow was made using the high-speed camera. Vijayan et al. [16] studied experimentally and theoretically the effect of loop diameter on the steady-state and stability behavior of single-phase and two-phase natural circulation loops. Garrity et al. [17] investigated instability phenomena in a two-phase thermosyphon loop consisting of a microchannel evaporator and a condenser. The comparison between the experimental and simulation results obtained for the mass flow rate was reasonable. Franco et al. [18] designed an experimental test rig. They analyzed the thermodynamic behavior of a working fluid in closed loop two-phase thermosyphon. Results showed that the mass flow rate increases with growing input power ranging approximately from 0 to $1.7 \mathrm{~kW}$. Higher instabilities were observed at higher heat loads. Authors presented a comprehensive review summarizing the results from many experimental studies for a small dimension two-phase closed-loop thermosyphon [19]. Khodabandeh [3,4] carried out extensive investigations on a rectangular thermosyphon loop with minichannels heated from below and cooled above with isobutane as a working fluid. The ex- 
perimental results show that the heat transfer coefficient increases with increasing heat flux. Chen et al. [20] studied rectangular thermosyphon loops with horizontal heat transfer sections. This investigation was focused on determining the optimum configuration of the loop based on both the convection heat transfer coefficient and friction factor. Dobson et al. $[21,22]$ simulated and experimentally verified the heat transfer and fluid flow in a rectangular thermosyphon loop with conventional channels and suggested that the proposed concepts for cooling can be used in the cooling system of the reactor cavity. Agostini et al. [1,23] proposed a solution of two-phase thermosyphon loop for the cooling of power electronics semiconductor modules. Their study shows potential use of the two-phase flow in the domain of electronic cooling and high-efficiency heat transfer from a source to a final cooling media. Cieśliński and Fiuk [24] studied experimentally the two-phase thermosyphon loop with horizontal evaporator and horizontal condenser using water, methanol and refrigerant R-141b as working fluids. Cieśliński [25] measured also the effect of concentration of the water-based $\mathrm{Al}_{2} \mathrm{O}_{3}$-nanofluid on thermal performance of the two-phase thermosyphon heat exchanger.

A natural circulation occurs in the thermosyphon loop. During the natural convection the heat is transported in the thermosyphon loop from a source to a sink. Fluid flow in a thermosyphon loop is created by the buoyancy force that evolves from the density gradients induced by temperature differences in the heating and cooling sections of the loop. An advanced two-phase thermosyphon loop consists of an evaporator, where the liquid boils; and a condenser, where the vapour condenses back to liquid; a riser and a downcomer connect these parts. Heat is transferred as the vaporization heat from the evaporator to the condenser. The thermosyphon is a passive heat transfer device, which makes use of gravity for returning the liquid to the evaporator. The thermosyphon loops are by far better solution than other cooling systems because they are pumpless. The closed loop thermosyphon is also known as a 'liquid fin' [26] (Fig. 1).

The single- and two-phase thermosyphon loops find many industrial applications $[27,28]$, such as, for example: distillation process, steam generators, thermosyphon reboilers, chemical reactors, emergency cooling systems in nuclear reactor cores and reflux boiling systems in light water reactor cores, solar heating and cooling systems, geothermal energy generation and thermal diodes $[6,7]$. The thermal diode is a device, which allows the heat to be transferred in one direction, and blocks the heat flow in the opposite 


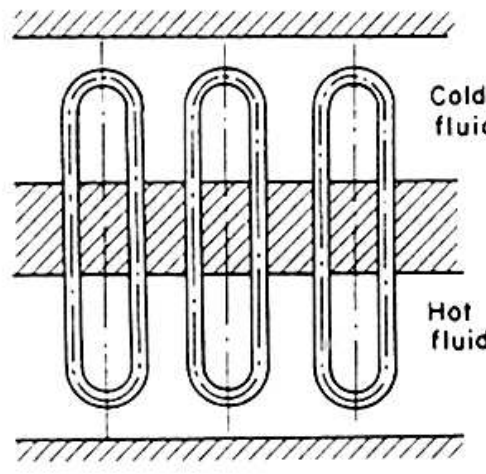

Figure 1: Schematic illustration of the liquid fin heated from below and cooled from above.

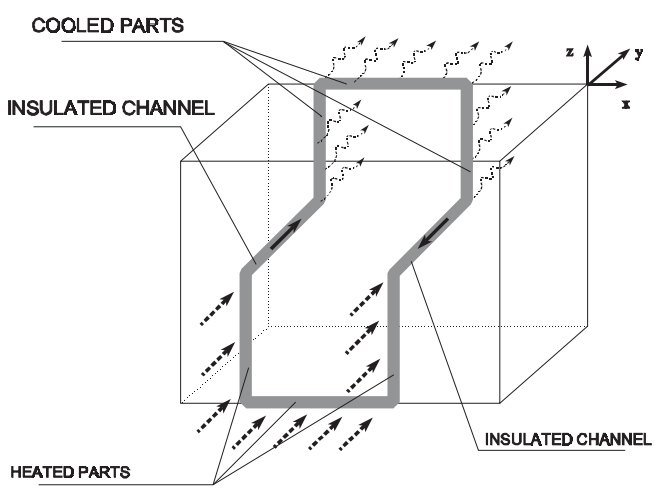

Figure 2: Schematic illustration of the thermal diode heated simultaneously from below and symmetrically from the sides.

direction (Fig. 2).

The thermosyphon effect is observed in loop heat pipe (LHP) if the evaporator is located below the condenser. A loop heat pipe is a completely passive heat transfer device, and consists of an evaporator, condenser, compensation chamber and some smooth transport lines for the vapour and liquid flows as shown in Fig. 3. The thermosyphon effect for cooling electronic devices can be applied in innovative miniature loop heat pipe (mLHP) with the evaporator located on the loop below the condenser.

The prototype of mLHP consists of a flat minievaporator and capillary pump. The porous wick material is placed inside capillary pump. The complete condensation of the medium takes place in a minicondenser. Both the mini-evaporator and mini-cooler are connected to the separate liquid and vapour channels. The high friction losses in mLHP can be reduced because the liquid/vapour phase flow in the separated channels and the porous wick is only present in minievaporator. The flat-shaped minievaporator is integrated with a capillary pump. The wicks generate the capillary pumping pressure, which is required to transport a working fluid along mLHP. The thermosyphon effect can also be applied in concept presented by Mikielewicz et al. [29] of micro-CHP-cogeneration where evaporator is located below condenser. The use of capillary forces for pumping of the working fluid in the Clausius-Rankine cycle is a new idea that allows the reduction or even the elimination of the pumping device in such cycles. It is also possible to exploit the gravity force to support the operation of a cir- 


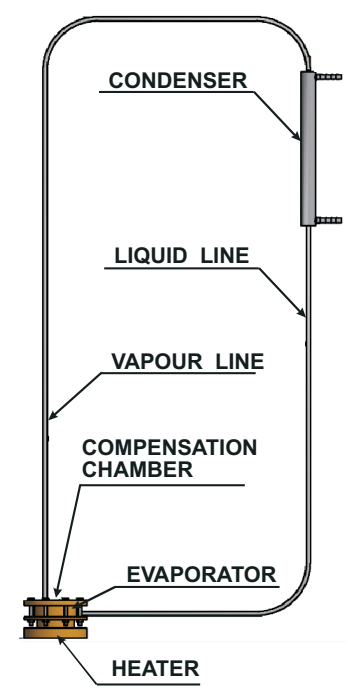

Figure 3: Idea scheme of miniature loop heat pipe (mLHP) with thermosyphon loop.

culation pump by placing the evaporator below the condenser and creating the thermosyphon loop.

In this study the presented variant of the rectangular thermosyphon loop with minichannels can be applied to describe the computer cooling system. The lower horizontal heater can be treated as a CPU processor located on the motherboard of personal computer and the lower vertical heater can simulate a chip located on vertical graphic card. The cooler must be placed above the heaters on the computer chassis. Heat exchangers are connected by minichannels filled with the liquid refrigerant.

\section{Theoretical investigations}

\subsection{The generalized model of two-phase thermosyphon loop}

A schematic diagram of the generalized model of two-phase thermosyphon loop is shown in Fig. 4. The thermosyphon loop is heated by three heaters in section: $\mathrm{H} 1\left(s_{0} \leq s \leq s_{1}\right), \mathrm{H} 2\left(s_{3} \leq s \leq s_{4}\right)$, and $\mathrm{H} 3\left(s_{6} \leq s \leq s_{7}\right)$ by a constant heat flux: $\dot{q}_{H_{1}}, \dot{q}_{H_{2}}, \dot{q}_{H_{3}}$, respectively and cooled from three coolers in section $\mathrm{C} 1\left(s_{8} \leq s \leq s_{9}\right), \mathrm{C} 2\left(s_{11} \leq s \leq s_{12}\right)$, and $\mathrm{C} 3\left(s_{14} \leq\right.$ $\left.s \leq s_{15}\right)$ by a constant heat flux $\dot{q}_{C_{1}}, \dot{q}_{C_{2}}, \dot{q}_{C_{3}}$, respectively. The heated 
and cooled regions of the thermosyphon loop are connected by perfectly insulated channels. The coordinate $s$ along the loop and the characteristic geometrical points on the loop are marked with $s_{n}$, as shown in Fig. 4. The total length of the loop is denoted by $L$, the internal diameter of the channel of the individual region is denoted by $D_{k}$, the cross-sectional area of the individual channel is denoted by $A_{k}$ and the wetted perimeter by $U_{k}$. Thermophysical properties of fluid: $\rho$-density, $c_{p}$ - specific heat at constant pressure, $\lambda$ - thermal conductivity.

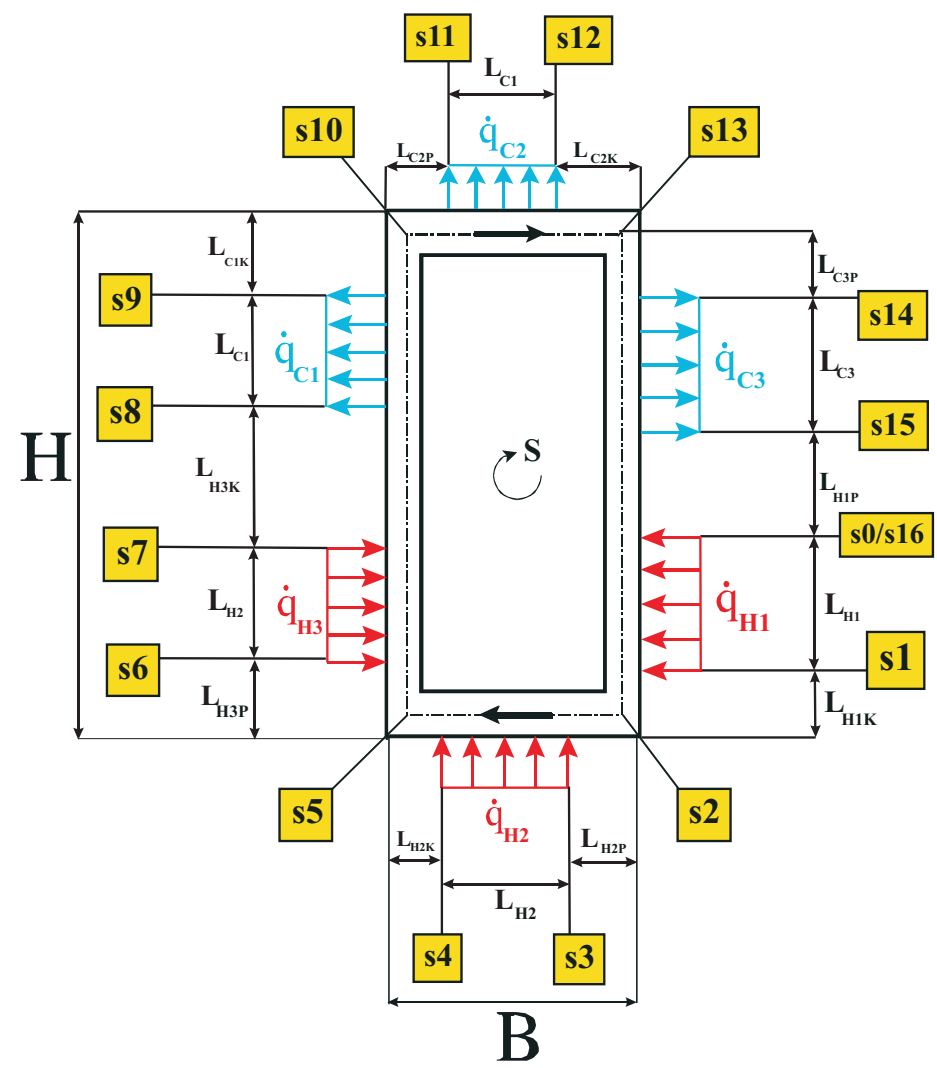

Figure 4: Schematic diagram of the generalized model of thermosyphon loop.

Using the generalized model it is possible to apply a different number of heaters and coolers. These heat exchangers can be placed at different locations on the loop. For example, the heat sources can be sitted at the bottom horizontal pipe or on the right/left vertical channels; similarly, the heat sinks can be chosen at the top horizontal pipe or on the right/left verti- 
cal channels. It is shown that this generalized model can be used to describe any possible individual variants of thermosyphon loop including the earlier variants developed by the author $[2,8-12]$. Fluid flow in a thermosyphon loop is created by the buoyancy force that evolves from the density gradients induced by temperature differences in the heating and cooling sections of the loop.

The following assumptions are made in this study:

1. Thermal equilibrium exists at any location of the loop.

2. Incompressibility, because the flow velocity in the natural circulation loop is relatively low compared with the acoustic speed of the fluid under current model conditions.

3. Viscous dissipation in the fluid is neglected in the energy equations.

4. $(D / L) \ll 1$; one-dimensional model is applied for the heat transfer and fluid flow in both single- and two-phase regions.

5. Fluid properties are constant, except density in the gravity term.

6. A linearly varying quality function $x(s)$ is assumed according to the study published in $[27,30,31]$.

7. Single-phase fluid and two-phase mixture can be selected as the working fluid:

(a) if the Boussinesq approximation is valid for a single-phase system, then density is assumed to vary as $\rho=\rho_{0}\left[1-\beta\left(T-T_{0}\right)\right]$ in the gravity term where $\beta=\frac{1}{v}\left(\frac{\partial v}{\partial T}\right)_{p},(v-$ specific volume, ' 0 ' is the reference steady state),

(b) two-phase friction factor multiplier $R_{2 P}$ is used to calculate the frictional pressure loss in heated, cooled and adiabatic two-phase sections in the two-phase system: $\Delta p_{2 P, F r}=R_{2 P} \times \Delta p_{L 0, F r}$;

(c) homogeneous or separated model of two-phase flow can be used to evaluate the friction pressure drop.

8. Two-phase mixture density $\rho$ is given by the weighting of void fraction $[17]$

$$
\begin{aligned}
& \rho=\left\{\begin{array}{cc}
\rho_{L} & \text { for liquid } \\
\rho_{V} & \text { for vapour }
\end{array}\right. \\
& \rho=(1-\alpha) \rho_{L}+\alpha \rho_{V} ; \quad \text { for two-phase mixture }
\end{aligned}
$$


9. Friction coefficient is constant in each region of the loop.

10. Changes of the potential energy in energy equation are neglected.

11. According to the model shown in Fig. 4 the incomplete evaporation and condensation of working fluid occurs in the heaters (H1), (H2), and $(\mathrm{H} 3)$, and in the coolers $(\mathrm{C} 1)$ and $(\mathrm{C} 2)$, respectively. It was assumed that the working fluid is treated as the two-phase medium in the region $\left(s_{0} \leq s \leq s_{15}\right)$.

12. It was assumed that the sections $\left\langle s_{1} ; s_{3}\right\rangle,\left\langle s_{4} ; s_{6}\right\rangle,\left\langle s_{7} ; s_{8}\right\rangle,\left\langle s_{9} ; s_{11}\right\rangle$ and $\left\langle s_{12} ; s_{14}\right\rangle$ are the adiabatic sections.

Due to the symmetry of the heating and cooling sections to the vertical axis, as shown in Fig. 4, the working fluid can flow incidentally in clockwise or counter clockwise direction. In case of the flow in clockwise direction two heaters $(\mathrm{H} 2, \mathrm{H} 3)$ force the circulation of fluid around the loop and the third heater (H1) prevents the circulation. In case of the flow in counter-clockwise direction, two heaters $(\mathrm{H} 2, \mathrm{H} 1)$ support the fluid circulation around the loop whereas the third one (H3) prevents the circulation. A good example for the technical solution responding to discussed cases can be the 'liquid fin' [26] or the 'thermal diode' $[6,7]$.

\subsection{The governing equations}

Under the above assumptions, the single-dimensional, steady-state governing equations for natural circulation in two-phase thermosyphon loop can be written as follows $[2,8-12]$ :

- conservation of mass:

$$
\frac{\partial \rho}{\partial \tau}+\frac{\partial}{\partial s}(\rho w)=0,
$$

where $\rho$ - mass density, $s$ - axial coordinate, $\tau$ - time, $w$ - velocity;

- conservation of momentum:

$$
\rho\left(\frac{\partial w}{\partial \tau}+w \frac{\partial w}{\partial s}\right)=-\frac{\partial p}{\partial s}+\varepsilon \rho \tilde{g}-\tau_{w} \frac{U}{A},
$$

where $\varepsilon=0$ for $\vec{e} \perp \vec{g}, \varepsilon=(+1)$ for $\vec{e} \uparrow \wedge \vec{g} \downarrow$, and $\varepsilon=(-1)$ for $\vec{e} \downarrow \wedge$ $\vec{g} \downarrow ; \tilde{g}=\vec{e} \cdot \vec{g}=g \cos (\vec{e}, \vec{g}) ;|\vec{g}|=g ;|\vec{e}|=1 ; \vec{g}$ is an acceleration vector, $\vec{e}$ is a versor of the coordinate around the loop, $\uparrow-$ sense of a vector and $\tau_{w}$ - wall shear stress; 
- conservation of energy:

$$
\frac{\partial T}{\partial \tau}+w \frac{\partial T}{\partial s}=a \frac{\partial^{2} T}{\partial s^{2}}+\left\{\begin{array}{ccc}
0 & \text { for } & \text { adiabatic section } \\
-\frac{q_{C} U}{c_{p} \rho} & \text { for } & \text { cooled section } \\
+\frac{\dot{q}_{H} U}{c_{p} \rho} & \text { for } & \text { heated section }
\end{array}\right\},
$$

where $a=\frac{\lambda}{\rho c_{p}}$ - thermal diffusivity, $c_{p}$ - specific heat at constant pressure, $U$ is the wetted perimeter.

Fluid flow and heat transfer can be considered in a steady-state analysis

$$
\frac{\partial}{\partial \tau}=0 \text {. }
$$

In order to eliminate the pressure gradient, the momentum term in Eq. (3) is integrated around the loop:

$$
\oint\left(\frac{d p}{d s}\right) d s=0, p(0)=p(L) .
$$

\subsection{Case for validation of the generalized model of two- phase thermosyphon loop}

The experimental measurements have been made for the case of the generalized model presented in Fig. 5. This two-phase thermosyphon loop consists of minichannels and conventional tubes. The thermosyphon loop is heated from the lower vertical section $\left(s_{3} \leq s \leq s_{4}\right)$ by a constant heat flux $\dot{q}_{H}$, and cooled in the upper vertical section $\left(s_{7} \leq s \leq s_{8}\right)$ by a constant heat flux, $\dot{q}_{C}$. The heated and cooled parts of the thermosyphon loop are connected by perfectly insulated channels.

As shown in Fig. 5 the space coordinate $s$ circulates around the loop. The following parameters of the lop are known: the coordinates of the characteristic points $s_{i}$, the internal diameter $D_{j}$, the cross-section area $A_{j}$, the wetted perimeter $U_{j}$ and the total length $L$. A linearly varying quality function $x(s)$ are assumed according to the study published in $[27,30,31]$.

The sum of acceleration pressure drops is neglected, because of the acceleration of the evaporating liquid in the evaporator is balanced by the deacceleration of the condensing vapour in the condenser in the thermposyphon loop [31]. Thus, by integrating around the loop, the momentum equation in (3) can be reduced to the form

$$
\oint_{L O O P}\left(\tau_{w} \frac{U}{A}\right) d s+\oint_{L O O P}(\varepsilon \rho \tilde{g}) d s=0 .
$$




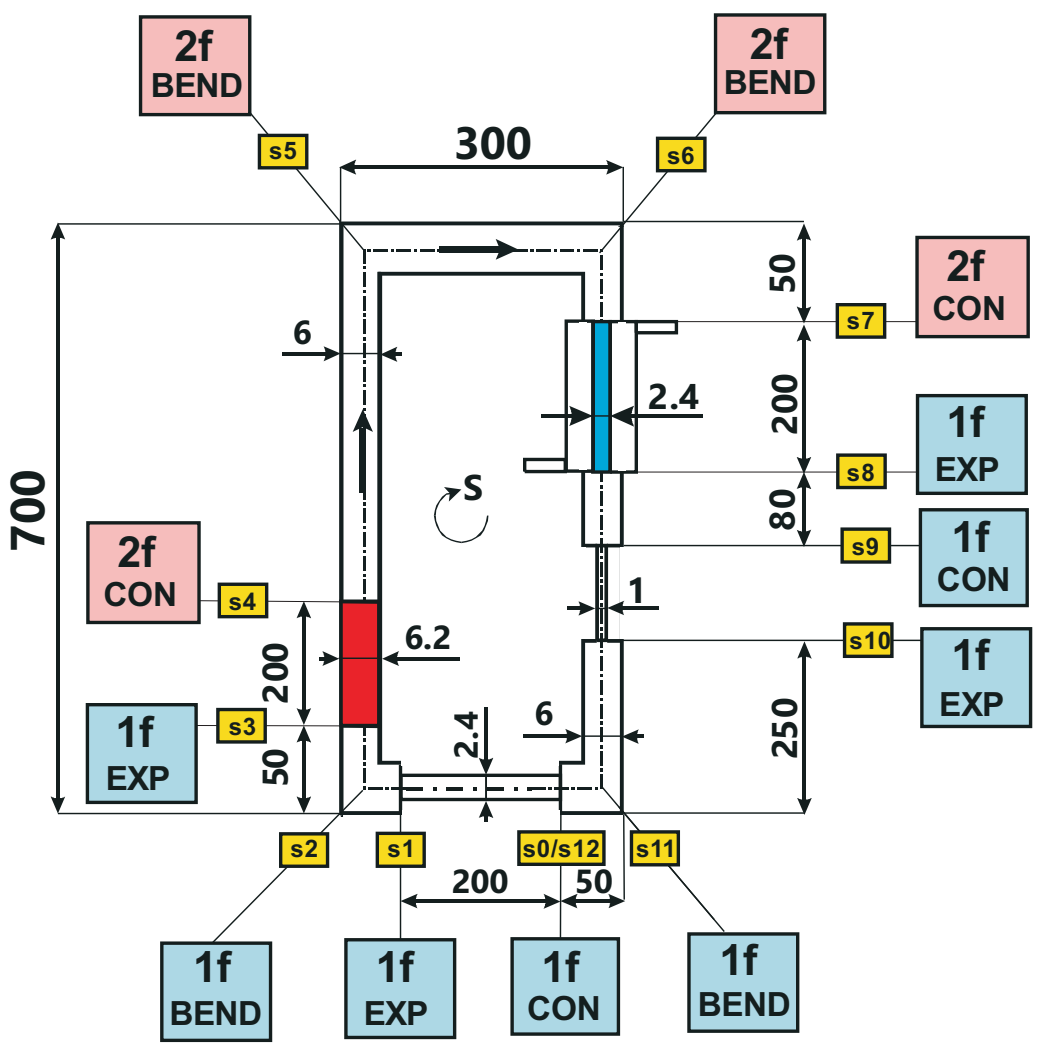

Figure 5: Theoretical model of the two-phase thermosyphon loop with minichannels and conventional tubes (BEND; EXP: sudden expansion; CON: sudden contraction.

\subsection{Gravitational term in the momentum equation}

The gravity term in the momentum Eq. (7) can be expressed as

$$
\begin{aligned}
& \oint_{L O O P}(\varepsilon \rho \tilde{g}) d s=g\left(\rho_{V}-\rho_{L}\right)\left\{\left(s_{4}-s_{3}\right) \bar{\alpha}_{\left\langle s_{3} ; s_{4}\right\rangle}+\right. \\
& \left.+\left[\left(s_{5}-s_{4}\right)-\left(s_{7}-s_{6}\right)\right] \bar{\alpha}_{\left\langle s_{4} ; s_{7}\right\rangle}-\left(s_{8}-s_{7}\right) \bar{\alpha}_{\left\langle s_{7} ; s_{8}\right\rangle}\right\},
\end{aligned}
$$

where

$$
\bar{\alpha}_{\left\langle s_{i} ; s_{j}\right\rangle}=\frac{1}{\left(s_{j}-s_{i}\right)} \int_{s_{i}}^{s_{j}} \alpha_{\left\langle s_{i} ; s_{j}\right\rangle}(s) d s .
$$




\subsection{Frictional term in the momentum equation}

In the thermosyphon loop during the fluid circulation, the following pressure losses $\triangle p_{T O T, F r}$ can be recognized: the pressure loss for overcoming the friction resistance in the pipes $\Delta p_{F r}$ and the pressure losses for overcoming the local resistance $\Delta p_{L O C}$ (bend, sudden expansion, sudden contraction).

$$
\Delta p_{T O T, F r}=\Delta p_{F r}+\Delta p_{L O C} .
$$

Two phase local pressure drop is calculated with

$$
\Delta p_{2 P, L O C}=\Psi_{L 0, L O C}^{2 P} \times \Delta p_{L 0, L O C},
$$

where $\Psi_{L 0, L O C}^{2 P}$ is a two-phase local loss multiplier and $\Delta p_{L 0, L O C}$ is a local pressure loss when all the mixture is liquid.

The frictional component of the pressure gradient in two-phase regions was calculated using the two-phase separated model. Due to friction of fluid, the pressure gradient in two-phase regions can be written as follows $[10,21]$ :

$$
\left(\frac{-d p}{d s}\right)_{2 P, F r}=R_{2 P}\left(\frac{-d p}{d s}\right)_{L 0, F r}
$$

where $R_{2 P}$ is the local two-phase friction factor, $\left(\frac{d p}{d s}\right)_{L 0, F r}$ is only the liquid frictional pressure gradient calculated for the liquid total volumetric flow rate. After integrating the friction term around the loop, we obtain

$$
\begin{aligned}
& \oint\left(\frac{d p}{d s}\right)_{F r, 2 P} d s= \\
& \quad=\left\{\left(\frac{d p}{d s}\right)_{L 0, F r}^{\left\langle s_{3} ; s_{4}\right\rangle}\left(s_{4}-s_{3}\right) \bar{R}_{\left\langle s_{3} ; s_{4}\right\rangle}+\left(\frac{d p}{d s}\right)_{L 0, F r}^{\left\langle s_{4} ; s_{7}\right\rangle}\left(s_{7}-s_{4}\right) \bar{R}_{\left\langle s_{4} ; s_{7}\right\rangle}+\right. \\
& \quad+\left(\frac{d p}{d s}\right)_{L 0, F r}^{\left\langle s_{7} ; s_{8}\right\rangle}\left(s_{8}-s_{7}\right) \bar{R}_{\left\langle s_{7} ; s_{8}\right\rangle}+\left(\frac{d p}{d s}\right)_{L 0, F r}^{\left\langle s_{0} ; s_{1}\right\rangle}\left(s_{1}-s_{0}\right)+ \\
& \quad+\left(\frac{d p}{d s}\right)_{L 0, F r}^{\left\langle s_{8} ; s_{9}\right\rangle}\left[\left(s_{9}-s_{8}\right)+\left(s_{12}-s_{10}\right)+\left(s_{3}-s_{1}\right)\right]+ \\
& \left.\quad+\left(\frac{d p}{d s}\right)_{L 0, F r}^{\left\langle s_{9} ; s_{10}\right\rangle}\left(s_{10}-s_{9}\right)\right\}
\end{aligned}
$$

where

$$
\bar{R}_{\left\langle s_{i} ; s_{j}\right\rangle}=\frac{1}{\left(s_{j}-s_{i}\right)} \int_{s_{i}}^{s_{j}} R(s) d s .
$$


Substituting Eqs.(8) and (13) and the sum of local resistance into the momentum Eq. (7) gives

$$
\begin{aligned}
& \left\{\left(\frac{d p}{d s}\right)_{L 0, F r}^{\left\langle s_{3} ; s_{4}\right\rangle}\left(s_{4}-s_{3}\right) \bar{R}_{\left\langle s_{3} ; s_{4}\right\rangle}+\left(\frac{d p}{d s}\right)_{L 0, F r}^{\left\langle s_{4} ; s_{7}\right\rangle}\left(s_{7}-s_{4}\right) \bar{R}_{\left\langle s_{4} ; s_{7}\right\rangle}+\right. \\
& \quad+\left(\frac{d p}{d s}\right)_{L 0, F r}^{\left\langle s_{7} ; s_{8}\right\rangle}\left(s_{8}-s_{7}\right) \bar{R}_{\left\langle s_{7} ; s_{8}\right\rangle}+\left(\frac{d p}{d s}\right)_{L 0, F r}^{\left\langle s_{0} ; s_{1}\right\rangle}\left(s_{1}-s_{0}\right)+ \\
& \quad+\left(\frac{d p}{d s}\right)_{L 0, F r}^{\left\langle s_{8} ; s_{9}\right\rangle}\left[\left(s_{9}-s_{8}\right)+\left(s_{12}-s_{10}\right)+\left(s_{3}-s_{1}\right)\right]+ \\
& \left.\quad+\left(\frac{d p}{d s}\right)_{L 0, F r}^{\left\langle s_{9} ; s_{10}\right\rangle}\left(s_{10}-s_{9}\right)\right\}+\sum_{i=1}^{12} \Delta p_{L O C_{i}}+g\left(\rho_{V}-\rho_{L}\right)\left\{\left(s_{4}-s_{3}\right) \bar{\alpha}_{\left\langle s_{3} ; s_{4}\right\rangle}+\right. \\
& \left.\quad+\left[\left(s_{5}-s_{4}\right)-\left(s_{7}-s_{6}\right)\right] \bar{\alpha}_{\left\langle s_{4} ; s_{7}\right\rangle}-\left(s_{8}-s_{7}\right) \bar{\alpha}_{\left\langle s_{7} ; s_{8}\right\rangle}\right\}=0 .
\end{aligned}
$$

In the case of minichannels, it is necessary to use new correlations for void fraction and the local two-phase friction coefficient in the two-phase region. The following correlations have been used to calculate the two-phase flow in the thermosyphon loop with minichannel:

- the El-Hajal et al. [33] correlation for void fraction,

- the Tran et al. [34] correlation for the friction pressure drop of twophase flow for $\left\langle s_{7} ; s_{8}\right\rangle$ the diabatic section and minichannels.

The following correlations have been used to calculate the two-phase flow in the thermosyphon loop with conventional tubes:

- the standard Zuber-Findlay [35] drift flux model of two-phase flow for void fraction,

- the Müller-Steinhagen and Heck [36] correlation for the friction pressure drop in two-phase flow for $\left\langle s_{3} ; s_{4}\right\rangle$ the diabatic region and conventional tube, and for $\left\langle s_{4} ; s_{7}\right\rangle$ the adiabatic region and conventional tube.

The following correlations have been used to calculate the local resistance of two-phase flow in the thermosyphon loop: 
Table 1: Correlations for the void fraction and the friction pressure drop of two-phase flow in minichannel.

\begin{tabular}{|c|c|}
\hline Researcher & Correlations for minichannel \\
\hline $\begin{array}{l}\text { El-Hajal } \\
\text { et al. }[33]\end{array}$ & $\begin{array}{l}\alpha_{H A J A L}=\frac{\alpha_{H O M}-\alpha_{S T E I N E R}}{\ln \left(\frac{\alpha_{H O M}}{\alpha_{S T E I N E R}}\right)} ; \alpha_{H O M}=\frac{1}{1+\frac{1-x}{x}\left(\frac{\rho_{V}}{\rho_{L}}\right)} \\
\alpha_{S T E I N E R}=\left(\frac{x}{\rho_{V}}\right) \times \\
\quad \times\left\{[1+0.12(1-x)] \times\left[\frac{x}{\rho_{V}}+\frac{1-x}{\rho_{L}}\right]+\frac{1.18(1-x)\left[g \sigma\left(\rho_{L}-\rho_{V}\right)\right]^{0.25}}{\dot{G}\left(\rho_{L}\right)^{0.5}}\right\}^{(-1)}\end{array}$ \\
\hline $\begin{array}{l}\text { Tran et } \\
\text { al. }[34]\end{array}$ & $\begin{array}{l}\left(\frac{d p}{d l}\right)_{2 P, F r}^{T R A N}=R_{L 0,2 P}^{T R A N} \times\left(\frac{d p}{d z}\right)_{F r, L 0} \\
R_{2 P, L 0}^{T R A N}=1+\left(4.3 Y^{2}-1\right) \times\left[N_{C O N F}(x)^{0.875}(1-x)^{0.875}+(x)^{1.75}\right] ; \quad \text { (17) } \\
N_{C O N F}=\frac{\left[\frac{\sigma}{g\left(\rho_{L}-\rho_{V}\right)}\right]^{0.5}}{D} ; Y=\sqrt{\left(\frac{d p}{d z}\right)_{V 0} /\left(\frac{d p}{d z}\right)_{L 0}} ;\end{array}$ \\
\hline
\end{tabular}

Table 2: Correlations for the void fraction and the friction pressure drop of two-phase flow in conventional tubes.

\begin{tabular}{|l|l|}
\hline Researcher & Correlations for conventional tube \\
\hline \hline Zuber-Findlay [35] & $\bar{\alpha}_{2 P}=\frac{1}{\left\{C_{0}\left[1+\left(\frac{1-x}{x}\right)\left(\frac{\rho_{V}}{\rho_{L}}\right)\right]+\frac{\rho_{V}}{G x} V_{v j}\right\}} ;$ \\
& $C_{0}=1.2 ; V_{v j}=1.53\left[g \sigma \frac{\left(\rho_{L}-\rho_{V}\right)}{\left(\rho_{L}\right)^{2}}\right] \quad\left(\frac{1}{4}\right) ;$ \\
\hline & \\
Müller-Steinhagen and & $\left(\frac{d p}{d s}\right)_{2 P, F r}^{M-S}=F(1-x)^{\frac{1}{3}}+B x^{3} ;$ \\
Heck [36] & $F=A+2 x(B-A) ; A=\left(\frac{d p}{d s}\right)_{L 0} ; B=\left(\frac{d p}{d s}\right)_{V 0} ; \quad$ (19) \\
\hline
\end{tabular}

\subsection{Simulation results}

A set of the enhanced procedures written in MATHCAD was developed for providing a simulation of a range of applications of the generalized model of the two-phase thermosyphon loop. A simulation code created for the presented experimental variant of the generalized model was used to solve 
Table 3: Correlations for the local resistance of two-phase flow.

\begin{tabular}{|c|c|}
\hline Fitting & Correlations for local resistance \\
\hline $\begin{array}{l}\text { Sudden } \\
\text { con- } \\
\text { traction } \\
{[37]}\end{array}$ & $\begin{array}{l}\Delta p_{2 P, C O N}=\Psi_{L 0, C O N}^{2 P} \times\left\{\frac{\left(\dot{G}_{1}\right)^{2}}{2 \rho_{L}} \times\left[\left(\frac{1}{C_{C}}-1\right)^{2}+1-\frac{1}{\left(\zeta_{C O N}\right)^{2}}\right]\right\} ; \\
\zeta_{C O N}=\left(\frac{A_{L A R G E}}{A_{S M A L L}}\right)=\left(\frac{A_{1}}{A_{2}}\right) ; \\
C_{C}=\left[\frac{1}{\left[0.639\left(1-\frac{1}{\zeta_{C O N}}\right)^{0.5}+1\right]}\right] ; \Psi_{L 0, C O N}^{2 P}=\left[1+x_{i n}\left(\frac{\rho_{L}}{\rho_{V}}-1\right)\right] ;\end{array}$ \\
\hline $\begin{array}{l}\text { Bend } \\
{[38,39]}\end{array}$ & $\begin{array}{l}\Delta p_{2 P, B E N D}=\Psi_{L 0, B E N D}^{2 P} \times \Delta p_{L 0, B E N D}=\Psi_{L 0, B E N D}^{2 P} \times\left[K_{L 0, B E N D} \frac{\left(\dot{G}_{1}\right)^{2}}{2 \rho_{L}}\right] \\
K_{L 0, B E N D}=1.14 ; B_{90}=1+\frac{2.2}{k_{L 0}^{90}\left[2+\left(\frac{R}{D}\right)\right]} ; \\
\Psi_{L 0, B E N D}^{2 P}=\left\{1+\left[\left(\frac{\rho_{L}}{\rho_{V}}-1\right) \times\left[B_{90} x_{i n}\left(1-x_{i n}\right)+\left(x_{i n}\right)^{2}\right]\right]\right\} ;\end{array}$ \\
\hline
\end{tabular}

the conservation equations of mass, momentum, and energy taking into account the measurement conditions in the experiment.

Further the effective procedures developed in this study were used to determine as follows:

- the characteristic geometrical points on the loop $s_{n}$;

- the void fraction of two-phase fluid in heater with conventional tubes and adiabatic section using the Zuber-Findlay [35] correlation and cooler with minichannel using the El-Hajal et al. [33] correlation;

- the local friction coefficient of two-phase flow in the selected circulation sections $\left\langle s_{3} ; s_{4}\right\rangle$ and $\left\langle s_{4} ; s_{7}\right\rangle$ of the thermosyphon loop using the Müller-Steinhagen and Heck [36] correlation for conventional tubes, the Tran et al. [34] correlation for minichannel $\left\langle s_{7} ; s_{8}\right\rangle$;

- the local flow resistance at characteristic points of the loop for a singleand two-phase flow in conventional diameter channel and minichannels.

Moreover, the code includes the iterative procedures for determination of the value of individual components of the of the momentum equation (16), e.g., the buoyancy term, local resistance and friction force of a single- and two-phase fluid flow in adiabatic and diabatic sections of the thermosyphon loop.

The results achieved by the use of the advanced analytical methods 
and numerical calculations are the predicted distribution of values for the volumetric flow rate due to the thermal power supplied to the heater. These calculations were performed assuming the same experimental conditions. Additionally, the comparisons are made between the results of homogeneous and separate flow models of two-phase flow formulation.

\section{$3 \quad$ Experimental investigations}

\subsection{Experimental setup}

The experiments described in this paper were undertaken using the experimental setup presented in Fig. 6. Photo of the experimental setup is shown in Fig. 7. This experimental setup was prepared for performing the validation of the generalized model using its new variant configuration analyzed in this study. The measurements were carried out on a two-phase thermosyphon loop with minichannels and conventional tubes. The termosyphon loop consists of an evaporator (single-conventional tube) on the lower vertical section and a condenser (single-minichannel tube) on the upper vertical section. Experimental apparatus consists of a thermosyphon loop device including evaporator, condenser, vertical tubes (riser and downcomer), horizontal connecting tubes, expansion tank and a set of instruments such as ultrasonic flow meter, power supply, ultra-thermostat, temperature acquisition instruments data acquisition system personal computer. The test loop of rectangular shape is $700 \mathrm{~mm}$ high and $300 \mathrm{~mm}$ width. The other geometrical dimensions of the loop are shown in Fig. 5.

The evaporator consisting of one conventional channel is located on the lower left part of the vertical section of the loop. The heater is made of a silver (AG935) tube of $200 \mathrm{~mm}$ length and $6.2 \mathrm{~mm}$ internal diameter. Silver has the best thermal conductivity of $429 \mathrm{~W} / \mathrm{mK}$. The silver tube of a heater is connected to a high-current electric circuit for a heating power supplier with autotransformer M10-522 and a high current shunt. The heating tube generates heat due to Joule heat. The amount of heat generated is regulated by the use of the variable M10-522 autotransformer. The voltage and current were measured by the AX8450 digital multimeters with the $\mathrm{AC}$ voltage measuring accuracy of $\pm 0.5 \%$.

The cooler consisting of a minichannel is located on the upper right part of the vertical section of the loop. The cooler is designed as a type of tubein-tube heat exchanger. The inner tube of the cooler is made of a silver tube of $200 \mathrm{~mm}$ length and $2.4 \mathrm{~mm}$ internal diameter. The outer tube of 


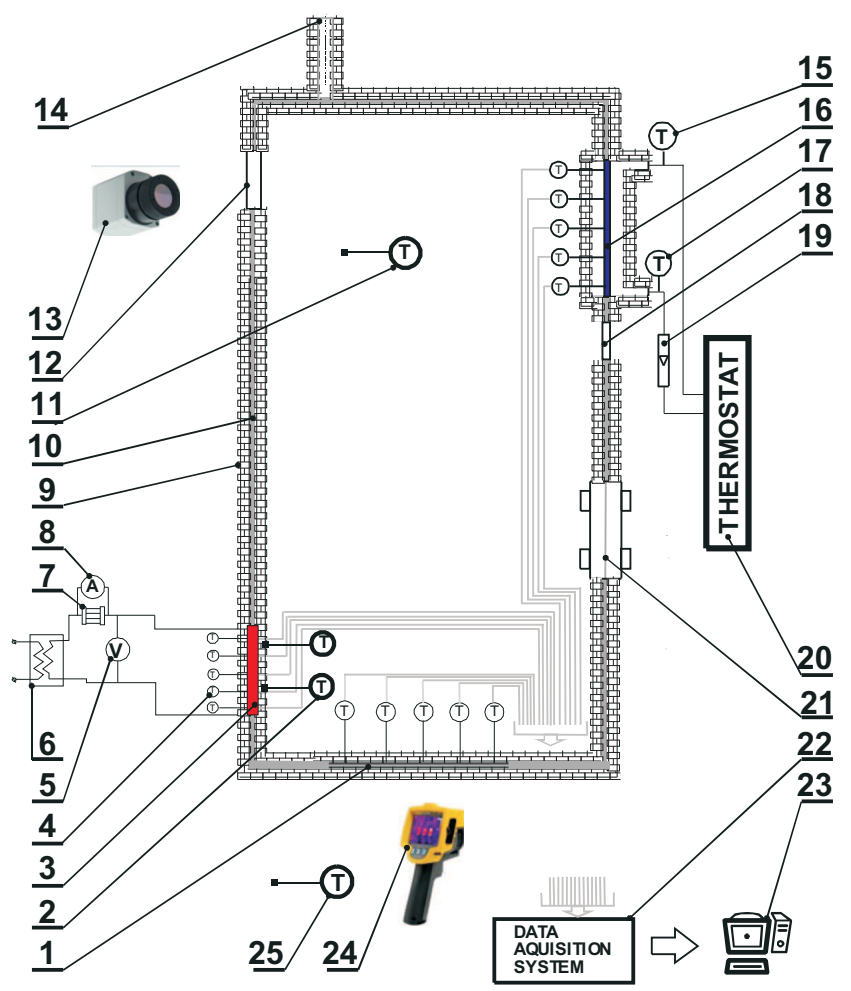

Figure 6: Schematic view of the experimental setup; 1 - minichannel, 2 - thermocouple (outer surface of insulation material), 3 - heater (conventional tube), 4 - thermocouple (outer surface of heater tube), 5 - voltmeter digital multimeter, 6 autotransformer, 7 - high current shunt, 8 - ampmeter digital multimeter, 9 - insulation, 10 - loop pipe, 11 - thermocouple (inside box), 12 - sight glass (left), 13 - camera, 14 - expansion tank, 15 - thermocouple (outlet of cooler), 16 - minichannel cooler tube, 17 - thermocouple (inlet of cooler), 18 - sight glass (right), 19 - rotameter, 20 - ultrathermostat, 21 - ultrasonic flow meter, 22 - data acquisition system, 23 - personal computer, 24 - infrared camera, 25 - thermocouple (ambient temperature).

the cooler is transparent and made of a plexiglass with an internal diameter of $40 \mathrm{~mm}$. The cooling fluid in the cooler flows in a countercurrent. The flow of coolant (distilled water) was forced by a pump ultra-thermostat MX07R-20-A12E PolyScience Refrigerated/Heated Circulating Bath with temperature stability of $\pm 0.07{ }^{\circ} \mathrm{C}$. The pump flow rate was $11.9 \mathrm{l} / \mathrm{min}$. 


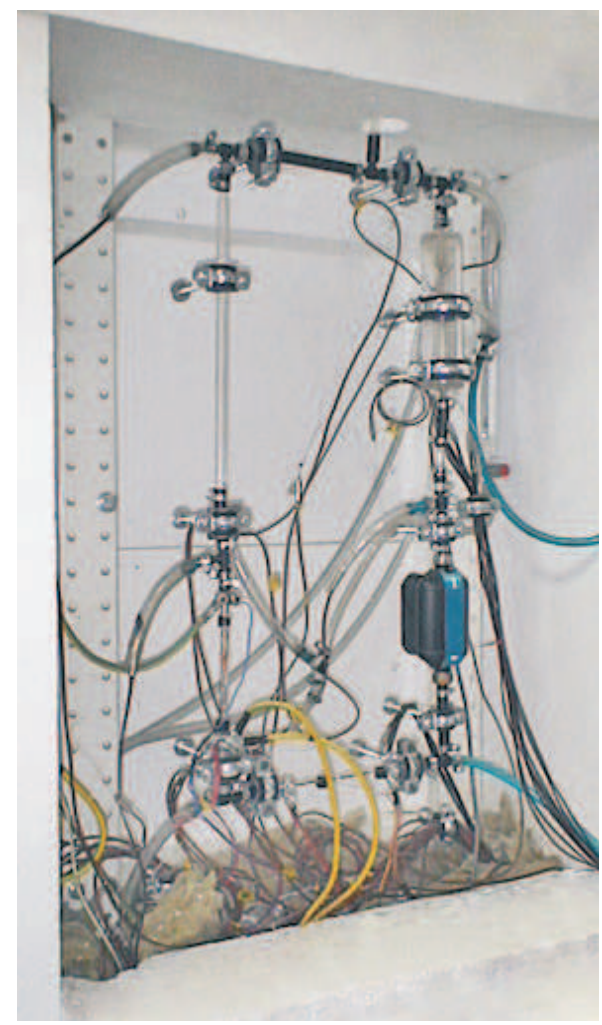

Figure 7: Photography of the experimental setup.

The flow rate for cooling fluid were adjusted by YOKOGAWA Rotameter RAGL53 with a high degree accuracy readings of $\pm 2.5 \%$. The $\mathrm{T}$ type thermocouples with $0.5 \mathrm{~mm}$ diameter and a measurement accuracy of $\pm 0.5{ }^{\circ} \mathrm{C}$ were used for temperature measurements. The thermocouples measured the temperature of the cooling fluid at the inlet and outlet of the condenser.

The test loop is thermally insulated using a high-temperature insulation material made of the ceramic mineral wool insulation blankets faced outwards with aluminum foil. The thickness and thermal conductivity of the insulation material are $30 \mathrm{~mm}$ and $\lambda=0.034 \mathrm{~W} / \mathrm{mK}$, respectively. The thermocouples measured the temperature of the outer surface of the insulated evaporator. The measurement setup is also thermally isulated in order to minimize the heat losses from the setup into the ambient. The whole measurement setup is covered by large solid box made of styrofoam 
with a thickness of $70 \mathrm{~mm}$ and a thermal conductivity of $\lambda=0.034 \mathrm{~W} / \mathrm{mK}$. The heat losses were determined using thermocouples located on the inner and outer walls of the insulated box. Moreover, the quality of insulation was controlled and monitored using FLIR A325sc infrared camera. It was found that the heat losses to the environment were negligible. The noncontact temperature measurements were curried out with accuracy of $\pm 2.0^{\circ} \mathrm{C}$ and $\pm 2.0 \%$ of reading. The thermal fluid flow was photographed and filmed through the sight glass of the loop tube with aid of the video camera JVC GC PX100BU.

An ultrasonic flow meter type Titan-Atrato AT710 was attached to the loop and connected directly to the data acquisition system (Model OMEGA USB-DAQ-2416-4AO). The calibrated flow meter was used for measuring and monitoring the volumetric flow rate of the circulating working fluid. This noninvasive flow meter detects changes in the flow of liquid through the small-bore tube and measures a small velocity of a fluid. The Titan-Atrato AT710 ultrasonic flow meter uses the time-of-flight measuring method. The important features of the Atrato ultrasonic flow meter are as follows: the operating capability up to $110{ }^{\circ} \mathrm{C}$, a high measurement dynamics (200:1 turndown and remote inputs), the measurement accuracy of $< \pm 1.5 \%$, and the excellent measuring repeatability of $0.1 \%$.

The data acquisition system type and the expansion module AI-EXP-32 with a resolution of 24 bit were used for recording the measured voltage from the thermocouples, flow meter and digital multimeter. The experimental loop has a small thermal expansion tank which was opened to the atmosphere. An ultrapure water as a working fluid was used in the experimental thermosyphon loop. The water was distilled, degassed, deionized and demineralized using Milli-Q Ultrapure Water Solutions Type 1.

The experimental test setup was configured for the presented variant. In fact, the experimental setup is designed and constructed for investigating the performance of any variants of the generalized model developed for the two-phase thermosyphon loop. This test station can be used to investigate the single- and two-phase flow circulation using different types of heat exchangers: minichannels, conventional tubes and a combination of minichannels and conventional tubes. It can be also applied for testing the thermosyphon effect in loop heat pipe. The presented model of the thermosyphon loop provides a basis for further experimental investigations and other parameters validation. 


\subsection{Experimental procedures}

First, after filling the thermosyphon with ultrapure water, the device was left out for approximately 24 hours in order to release possible bubbles in the loop. Then, the temperature of the cooling water was determined in the operating thermostat MX07R-20-A12E. The flow rate for cooling water was adjusted by Yokogawa Rotameter RAGL53.

Next, the recording device OMEGA USB-DAQ-2416-4AO, expansion module AI-EXP-32 and computer software for data logging were launched. The heating system was started up. The amount of generated heat was regulated by the variable output voltage of M10-522 autotransformer.

Finally, the measured data of volumetric flow rate and the temperature of all used thermocouples were recorded during transient and steady-state flow. The averaged value of volumetric flow rate was determined when the measured distribution of volumetric flow rate at steady-state reached a plateau. This procedure was repeated at successively higher values of heat power between $14 \mathrm{~W}-38 \mathrm{~W}$. The upper limit of the heat power was not exceeded to avoid the occurrence of the dry-out phenomenon and destruction of the silver tube heater due to overheating. A large number of the volumetric flow rate measurements were made throughout this work. The obtained results were replicable.

\subsection{Uncertainty analysis}

The experimental errors were determined according to the ISO GUM [40] uncertainty methods of type A and B. The experimental measurements were influenced by the statistical, standard deviations (type A) and the nonstatistical, expected uncertainty of the measuring system (type B).

An estimation of the square of the overall combined uncertainty is achieved by summing the squares of the type A and B uncertainties:

$$
u_{C}(y)=\sqrt{u_{A}^{2}(y)+u_{B}^{2}(y)},
$$

where $u_{A}(y)$ is the uncertainty of type A

$$
u_{A}(y)=\sqrt{\frac{1}{N(N-1)} \sum_{i=1}^{N}\left(x_{i}-\bar{x}\right)^{2}} ; \text { and } \bar{x}=\sqrt{\frac{1}{N} \sum_{i=1}^{N} x_{i}},
$$

where $x_{i}$ is the $i$ th individual value, and $N$ is the number of observations. The expected uncertainty of the measuring system (type B) was based on 
the principle of uncertainties propagation. The uncertainty of a function $f$ of several independent variables $x_{i}$ provided all errors associated with these independent variables and is given by formula

$$
u_{B}(y)=\sqrt{\left[\sum_{i=1}^{N}\left(\frac{\partial f}{\partial x_{i}}\right) u\left(x_{i}\right)\right]^{2}},
$$

where $y=f\left(x_{1}, x_{2}, \ldots, x_{N}\right)$ and $u\left(x_{i}\right)$ is the uncertainty of variable $x_{i}$. The expanded uncertainty of measurement $U$ was obtained by multiplying the standard uncertainty $u_{C}(y)$ by a coverage factor $k$ as follows:

$$
U(y)=k u_{C}(y) .
$$

The standard coverage factor was used. The assigned expanded uncertainty corresponds to a coverage probability of approximately $95 \%$.

The uncertainties in the experimental results were associated with direct measurements. Table 4 presents the uncertainty values of instruments used in the present work.

Table 4: Uncertainty of instruments used in this research.

\begin{tabular}{|l|l|l|}
\hline \multicolumn{1}{|c|}{ Parameter } & \multicolumn{1}{c|}{ Instrument } & \multicolumn{1}{c|}{ Uncertainty } \\
\hline \hline Voltage U $[\mathrm{V}]$ & Multimeter AX8450 & \pm 0.6 \\
\hline Current I $[\mathrm{A}]$ & Multimeter AX8450 & \pm 0.002 \\
\hline Volumetric flow rate & Atrato AT710 & $< \pm 1.5 \%$ of reading \\
\hline Temperature $\left[{ }^{\circ} \mathrm{C}\right]$ & thermocouples type T/0.5 & \pm 0.5 \\
\hline
\end{tabular}

The heating power input $\dot{Q}$ can be computed by Eq. (26) as follows:

$$
\dot{Q}=U I,
$$

where $I$ is the current, $U$ is the voltage. The uncertainty of the heating power input $\dot{Q}$ was obtained by the following equation:

$$
u_{B}(\dot{Q})=\sqrt{\left[\left(\frac{\partial \dot{Q}}{\partial U}\right) u_{B}(U)\right]^{2}+\left[\left(\frac{\partial \dot{Q}}{\partial I}\right) u_{B}(I)\right]^{2}} .
$$

The expanded uncertainty for the volumetric flow rate and the heat power in the evaporator were determined as $U(\dot{V})= \pm 0.17 \mathrm{~mL} / \mathrm{min}$ and $U(\dot{Q})=$ $\pm 1 \mathrm{~W}$, respectively. 


\section{Experimental results}

Figure 8 presents the experimental results for five measuring series of the volumetric flow. The results were obtained for five values of heat power $(19 \mathrm{~W}, 22 \mathrm{~W}, 26 \mathrm{~W}, 31 \mathrm{~W}, 35 \mathrm{~W})$ in one experimental session. The applied heating loads were set without interrupting fluid circulation. Thus, the separate series of measurements in terms of heat power can be analyzed.

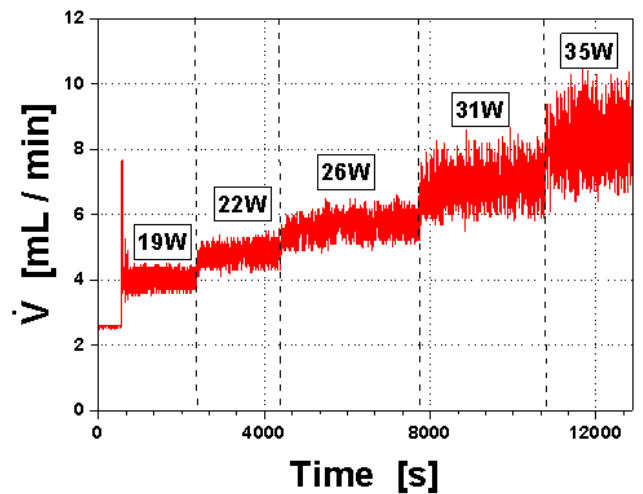

Figure 8: Experimental volumetric flow rates vs. time of recording for tested range of hear power.

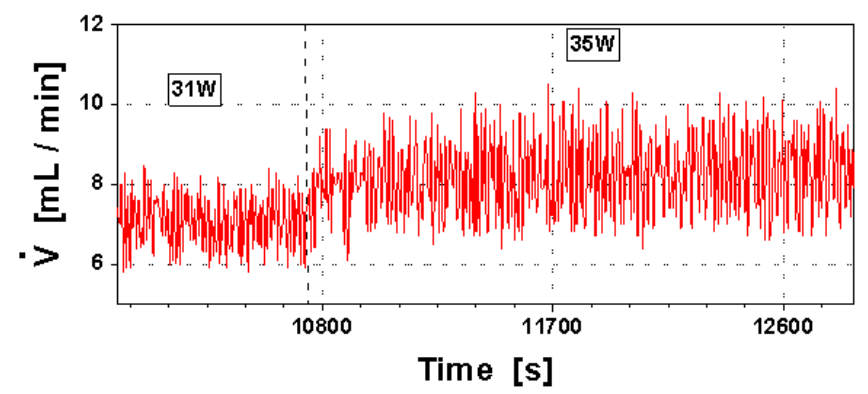

Figure 9: Measured volumetric flow rates vs. time of recording for two values of heating loads $(31 \mathrm{~W}, 35 \mathrm{~W})$.

Figure 9 shows the measured volumetric flow rate for the cases of applied power equal to $31 \mathrm{~W}$ and $35 \mathrm{~W}$ heating loads with zooming the time scale. The transient and steady-state sectors are clearly seen. 
The oscillations in frequency and amplitude of the volumetric flow rate were observed across the full measurement range of the heating load. The relatively small amplitude values of the volumetric flow rate were observed by lower settings of the heat rate $(19 \mathrm{~W}, 22 \mathrm{~W}, 26 \mathrm{~W})$ applied to the evaporator of the thermosyphon loop. The relatively larger amplitude of the volumetric flow rate was observed with the increasing the heating loads $(31 \mathrm{~W}, 35 \mathrm{~W})$. The average value of volumetric flow rate were calculated individually for each series of measurements. The calculations were based on the instantaneous values of volumetric flow rate measured by the ultrasonic flow meter. It was found that during power start-up for each series of measurements the average value of the volumetric flow rate was increasing with time. But after this initial transient flow the average value of the volumetric flow rate reached a plateau. The values of the volumetric flow rate remain constant under steady-state conditions. Both transient and steady-state flows can be identified by each series of measurements. In fact, the steady-state played a dominant role during the measurements of the volumetric flow rate of the two-phase flow in the thermosyphon loop. Furthermore, it was observed that there is a large instantaneous value of the volumetric flow rate at low power start-up $(19 \mathrm{~W})$. The phenomenon of very high amplitude oscillation of flow rate was also observed and reported by Archana et. al [14] and Vijayan et al. [16]. The authors concluded that the high peak of amplitude occurs in the first unstable zone.

Results obtained for a set of the average values of the volumetric flow rate at the steady-state for all series of experimental data are presented in Fig. 10. Additionally, figure demonstrates the comparison between the results of homogeneous and separated two-phase flow models.

The experimental values of the volumetric flow rate and those obtained with the generalized model of two phase flow in thermosyphon loop using in calculations the homogenous and separated two-phase flow models are of the same order of magnitude. A good agreement can be seen by comparing the experimental values of the volumetric flow rate to the theoretical values using the separated two-phase flow model.

Moreover, the thermal behavior of the two-phase flow was photographed and filmed through the sight glass of the loop tube. Figure 11 presents photos of the two-phase flow structure observed after the fluid left the heater. In Figs. 11 (a) and (b) are shown the bubble flow at $19 \mathrm{~W}$ and $22 \mathrm{~W}$, respectively. But the plug flow pattern was observed at $31 \mathrm{~W}$. 


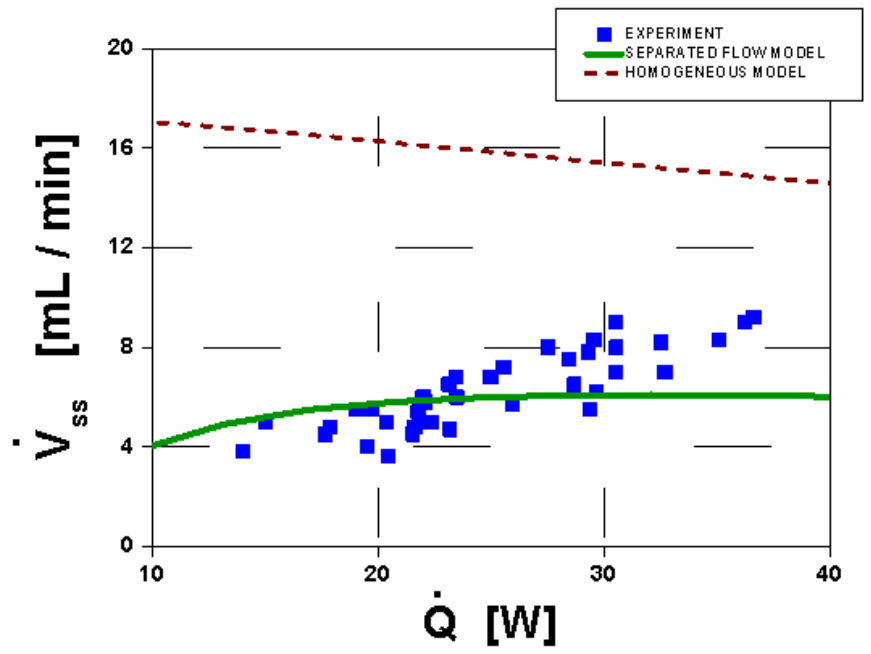

Figure 10: Comparison of the experimental average volumetric flow rate and values predicted by the homogeneous and separated two-phase flow model formulations.

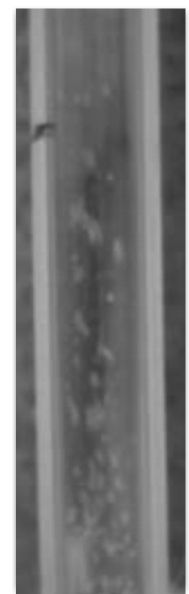

(a)

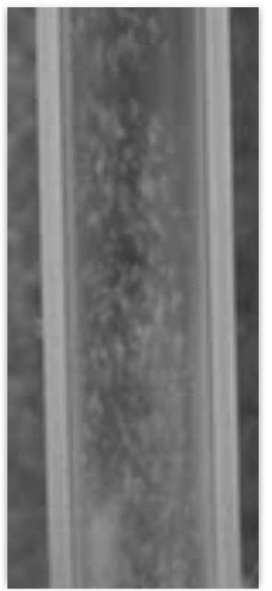

(b)

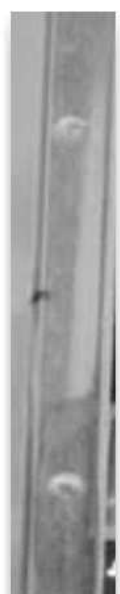

(c)

Figure 11: The flow boiling patterns observed through the evaporator transparent wall: (a) and (b) - bubble flow at $19 \mathrm{~W}$ and $22 \mathrm{~W}$, respectively; (c) - plug flow at $31 \mathrm{~W}$. 


\section{Conclusions}

Both theoretical and experimental investigations have been carried out to study the heat transfer and fluid flow in two-phase thermosyphon loop with minichannels and conventional tubes. The goal of this research was to provide an experimental validation of the generalized theoretical model of the two-phase thermosyphon loop. A new variant of the generalized model was investigated for the purpose of improving agreement with experimental data. The model refers to a thermosyphon loop with minichannels and conventional tubes. The thermosyphon loop consists of the evaporator on the lower vertical section and the condenser on the upper vertical section. The presented thermosyphon loop configuration with the evaporator (single-conventional tube) and condenser (single-minichannel tube) was not experimentally investigated by other researchers.

The heat transfer characteristics of the thermosyphon loop with minichannels and conventional tubes based on the one-dimensional two-phase separated flow model can be predicted using the following correlations: in case of minichannels - the El-Hajal [33] correlation for void fraction, the Tran [34] correlation for the friction pressure drop of two-phase flow in the cooling region; in the case of conventional tubes - the standard Zuber-Findlay [35] drift flux model of two-phase flow correlation for void fraction, the Müller-Steinhagen and Heck [36] correlation for the friction pressure drop in two-phase flow for $\left\langle s_{3} ; s_{4}\right\rangle$ the heating region, and for $\left\langle s_{4} ; s_{7}\right\rangle$ the adiabatic region.

The oscillations in frequency and amplitude of the volumetric flow rate were observed across the full measurement range of the heating load. It was found that after this initial transient flow the average value of the volumetric flow rate reached a plateau. The values of the volumetric flow rate remain constant under steady-state conditions. The steady-state conditions played a dominant role during the two-phase flow in thermosyphon loop. The flow rate oscillations in two-phase thermosyphon loops and the constant value of the volumetric and mass flow rate under steady-state conditions were also identified and reported by Archana et al. [14], Vijayan et al. [16], Lemos et al. [15].

It is found that the values of the volumetric flow rate obtained experimentally and those obtained with the generalized model of two-phase flow in thermosyphon loop using in calculations the homogenous and separated two-phase flow models are of the same order of magnitude. A good agreement is observed between the experimental results and the theoretical 
predictions using the separated two-phase flow model. The values of volumetric flow rate derived from the homogenous model of two-phase flow are higher than those obtained by experiment. This means that the homogeneous model of two-phase flow is too rough and does not reflect the nature of the circulation of fluid in the two-phase thermosyphon loop.

The presented results provide the experimental evidence for the validity of the proposed concept of the generalized model of two-phase thermosyphon loop. The results from the study show that this generalized model can be used to describe any possible individual variants of thermosyphon loop with minichannels including the earlier variants developed by authors [2, 8-12]. The best choice of the variant is dependent on specific conditions of cooling needs.

The presented experimental setup offers various technical solutions which provide a basis for further experimental investigations and other parameters validation. Further studies are required, for example, to verify the other variants of the generalized model previously analyzed by author and to gain knowledge about the effect of a working fluid and the geometrical parameters on the thermal performance of the thermosyphon loop. These parameters are important and practical for electronic cooling applications. The results obtained from the generalized model of two-phase thermosyphon loop can form the basis for further investigations.

Acknowledgement The work presented in the paper was funded from the National Science Centre Poland: project No: NCN-UMO-2011/01/B/ ST8/06856.

Received 22 November 2016

\section{References}

[1] Agostini F., Gradinger T., Cottet D.: Compact gravity driven and capillarysized thermosyphon loop for power electronics cooling. J. Thermal Sci. Eng. Appl. 6(2014), 3, 031003-1.

[2] Bieliński H., Mikielewicz J.: Computer cooling using a two phase minichannel thermosyphon loop heated from horizontal and vertical sides and cooled from vertical side. Arch. Thermodyn. 31(2010), 4, (2010), 51-59.

[3] Khodabandeh R.: Heat transfer in the evaporator of an advanced two-phase thermosyphon loop. Int. J. Refrig. 28(2005), 2, 190-202.

[4] Khodabandeh R.: Pressure drop in riser and evaporator in an advanced two-phase thermosyphon loop. Int. J. Refrig. 28(2005), 725-734. 
[5] Kumar K.K., Gopal M.R.: Experimental studies on CO2 based single and twophase natural circulation loops. Appl. Therm. Eng. 31(2011), 16, 3437-3443.

[6] Bieliński H., Mikielewicz J.: Natural convection of thermal diode. Arch. Thermodyn.16(1995), 3-4, 177-196.

[7] Bieliński H., Mikielewicz J.: New solutions of thermal diode with natural laminar circulation. Arch. Thermodyn. 22(2001), 1-2, 89-106.

[8] Bieliński H., Mikielewicz J.: The effect of geometrical parameters on the mass flux in a two phase thermosyphon loop heated from one side. Arch. Thermodyn. 29(2004), 1, 59-68.

[9] Bieliński H., Mikielewicz J.: A two phase thermosyphon loop with minichannels heated from vertical side and cooled from horizontal side. Chem. Process Eng. 31(2010), 4, 535-551.

[10] Bieliński H., Mikielewicz J.: Natural circulation in single and two phase thermosyphon loop with conventional tubes and minichannels. In: 'Heat Transfer. Mathematical Modeling, Numerical Methods and Information Technology' (A. Belmiloudi, Ed.), InTech , 2011, 475-496.

[11] Bieliński H.: New variants to theoretical investigations of thermosyphon loop. In: 'Two Phase Flow, Phase Change And Numerical Modeling' (A. Ahsan, Ed.) InTech (ISBN 978-953-307-584-6), Chap. 16, 2011, 365-386.

[12] Bieliński H., Mikielewicz J., Mikielewicz, D.: A closed loop thermosyphon with conventional or minichannel based condenser and evaporator. 16th Int. Heat Pipe Conf. (16th IHPC), Lyon, May 20-24, (2012).

[13] Lamaison N., Ong C.L., Marcinichen J.B., Thome J.R.: Two-phase minithermosyphon electronics cooling: Dynamic modeling, experimental validation and application to 2U servers. Appl. Therm. Eng. 110(2017), 481-494.

[14] Archana V., VAidya A.M., Vijayan P.K.: Flow transients in supercritical $\mathrm{CO}_{2}$ natural circulation loop. Procedia Eng. 127(2015). 1189-1196.

[15] Lemos W.L., Faccini H.L.H., Sul J.: Flow Visualization Of Bubble Behavior Under Two-Phase Natural Circulation Flow Conditions Using High Speed Digital Camera. 2013 Int. Nuclear Atlantic Conf. - INAC 2013, Recife, PE, November 2429, 2013, Associao Brasileira De Energia Nuclear - ABEN.

[16] Vijayan P.K., Nayak A. K., Saha D., and Gartia M.R.: Effect of loop diameter on the steady state and stability behaviour of single-phase and two-phase natural circulation loops. Hindawi Publ. Corp. Sci. Technol. of Nuclear Installations, 2008, ID 672704,17 .

[17] Garrity P.T., Klausner J.F., Mei R.: Instability phenomena in a two-phase microchannel thermosyphon. Int. J. Heat Mass Tran. 52(2009), 7-8, 1701-1708.

[18] Franco A., Filippeschi S.: Closed loop two-phase thermosyphon of small dimensions: A Review of the experimental results. Microgravity Sci. Tec. 24(2012), 3, $165-179$.

[19] Franco A., Filippeschi S.: Experimental analysis of closed loop two phase thermosyphon (CLTPT) for energy systems. Exp. Therm. Fluid Sci. 51(2013), 302-311. 
[20] Chen L., Deng Bi-Li, Zhang Xin-Rong: Experimental study of trans-critical and supercritical CO2 natural circulation flow in a closed loop. Appl. Thermal Eng. 59(2013), 1-2, 1-13.

[21] Dobson R.T., Ruppersberg J.C.: Flow and heat transfer in a closed loop thermosyphon. Part I -Theoretical simulation. J.Energ. South. Africa 18(2007), 4, 3240.

[22] Dobson R.T., Ruppersberg J.C.: Flow and heat transfer in a closed loop thermosyphon Part II - experimental simulation. J. Energ. South. Africa 18(2007), 3, $41-48$.

[23] Agostini F., Ferreira E.: Non intrusive measurement of the mass flow rate inside a closed loop two-phase thermosyphon. In: Proc. 8th Minsk Int. Seminar 'Heat Pipes, Heat Pumps, Refrigerators, Power Sources', Minsk, Belarus, Sept. 12-15, 2011.

[24] CieśLiński J.T., FIUK A.: Heat transfer characteristics of a two-phase thermosyphon heat exchanger. Appl. Thermal Eng. 51(2013), 1-2, 112-118.

[25] CiEŚLIŃSKI J.T.: Effect of nanofluid concentration on two-phase thermosyphon heat exchanger performance. Arch. Thermodyn. 37(2016), 2, 23-40, DOI: 10.1515/aoter2016-0011.

[26] Madejski J., Mikielewicz J.: Liquid fin a new device for heat transfer equipment. Int. J. Heat Mass Tran. 14(1971), 357-363.

[27] Won Tae Kim, Kwang Soo Kim, Young Lee: Design of a two-phase loop thermosyphon for telecommunications system (II). Analysis and simulation. KSME Int. J. 12(1998), 5, 942-955.

[28] Mertol A., Greif R.: A review of natural circulation loops. In Natural Convection: Fundamentals and Applications (1985), 1033-1071.

[29] Mikielewicz D., Szymański P., BŁauciak K., Wajs J., Mikielewicz J., IhnaTOWICZ E.: The new concept of capillary forces aided evaporator for application in domestic organic Rankine cycle. Heat Pipe Sci. Technol., Int. J. 1(2010), 4, 359-373.

[30] Rao N.M., Sekhar Ch., Maiti B., Das P.D.: Steady-state performance of a two-phase natural circulation loop. Int. Commun. Heat Mass Trans. 33 (2006), 1042-1052.

[31] Hartenstine J.R., Bonner R.W., Montgomery J. R., Semenic S.: LOOP Thermosyphon design for cooling of large area, high heat flux sources. In: Proc. IPACK2007 ASME InterPACK '07, July 8-12, 2007, Vancouver, British Columbia, Canada, IPACK2007-33993.

[32] Ghiahian S.M.: Two-Phase Flow, Boiling and Condensation in Conventional and Miniature Systems.Cambridge University Press, 2008, ISBN 978-0-521-88276-7.

[33] El-Hajal J., Thome J.R., Cavallini A.: Condensation in horizontal tubes. Part 1: Two-phase flow pattern map. Int. J. Heat Mass Tran.46(2003), 18, 3349-3363.

[34] Tran T.N., Chyu M.C., Wambsganss M.W., France D.M.: Two-phase pressure drop of refrigerants during flow boiling in small channels: An experimental investigations and correlation development. Int. J. Multiphase Flow, 26(2000), 11, 1739-1754.

[35] Zuber N., Findlay J.A.: Average volumetric concentration in two-phase flow systems. J. Heat Trans. 87(1965), 4, 453-468. 
[36] Müller-Steinhagen H., Heck K.: A simple friction pressure drop correlation for two-phase flow in pipes. Chem. Eng. Processes 20(1986), 6, 297-308.

[37] HewitT G.F.: Two-phase flow through orifices, valves, bends and other singularities. In: Proc. 9th Lecture Series on Two-Phase Flow, Norwegian Institute of Technology, Trondheim (1984), 163.

[38] Chisholm D.: Two-phase flow in bends. Int. J. Multiphase Flow 6(1979), 4, 363367.

[39] IdelchiK I.E.: Handbook of Hydraulic Resistance. 2nd Edn. New York: Hemisphere, 1986.

[40] ISO GUM EA-4/02 Evaluation of the Uncertainty of Measurement in Calibration., EA Laboratory Committee. 